\title{
A Polêmica em Torno do Conceito de Estresse
}

Este trabalho procurou explicitar a polêmica que existe em torno do conceito de estresse. Para isso, apresentamos dois pontos de vista: um a favor e outro contra a utilização científica do termo. Verificamos que sua definição é ainda um tanto imprecisa, o que não impede que alguns trabalhos sobre o estresse desenvolvidos por profissionais sérios tenham apresentado bons resultados.

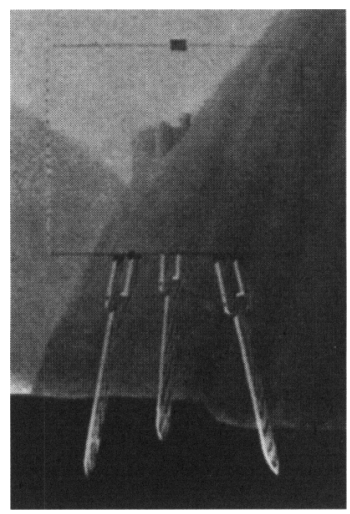

Julio Cesar Filgueiras Acodernico do ustimo periodo de psicologia da Universidade federal de tuiz de fora. Atuolmente desenwolve um trobatho de fingt de curso estudando as fatores emolvidos no odoecimento dos trobathodores em uma indústria olimenticia.

Maria Isabel Steinherz Hippert Acodemica do untimo periodo de psicotogio do universido de feder al de tuiz de fora.

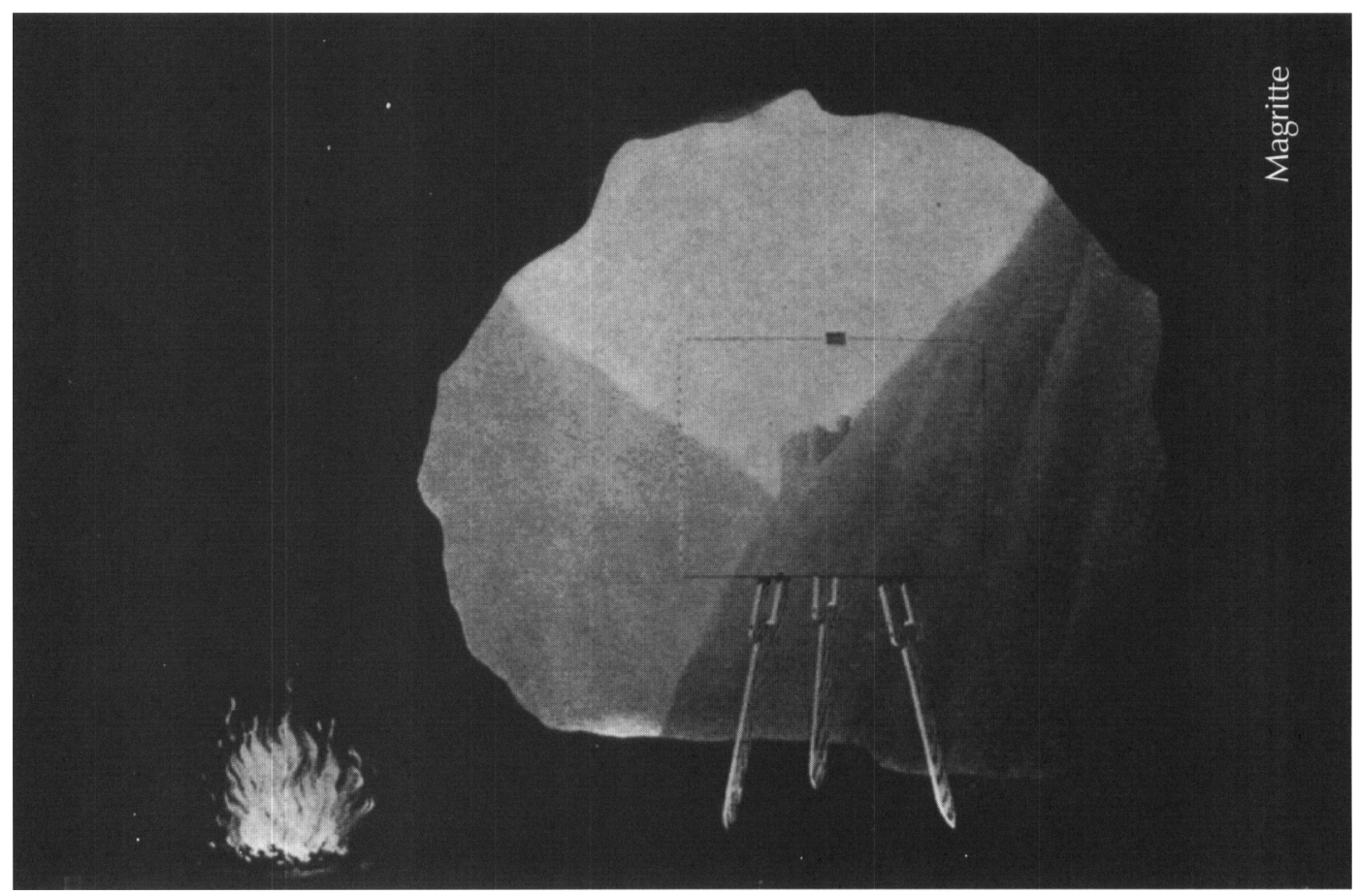

$O$ conceito de estresse tem sido amplamente utilizado nos dias atuais, chegando mesmo a tornar-se parte do senso comum. Podemos observar que os meios de comunicação de massa têm veiculado o conceito de forma indiscriminada, o que favorece uma certa confusāo a respeito do verdadeiro significado do termo. $O$ estresse passou a ser responsável por quase todos os males que no: afligem atualmente, principalmente em decorrência da vida moderna. Em vista disso, nāo é de se espantar que tenha havido um crescimento de terapêuticas e de programas voltados para o controle do estresse. Muitos desses programas carecem de um embasamento teórico mais aprofundado, enquanto outros sào desenvolvidos por profissionais sérios e competentes. Além do interesse científico, também cresceu o interesse econômico em torno do estresse, que pode ser observado tanto na indústria farmacêutica, que vem fabricando numerosos produtos para combatê. lo, como nas companhias de seguro, principalmente norte-americanas. Segundo pesquisas recentes (Robbins, 1993, apud Doublet, 1998), o estresse está relacionado às queixas de aproximadamente dois terços das consultas médicas realizadas nos Estados Unidos. Além disso, a ele é atribuído um elevado índice de absenteísmo e de licenças médicas nas organizaçôes. 
Numa tentativa de situar o conceito de estresse nas pesquisas atuais, e năo tendo a intenção de esgotar assunto tão amplo, decidimos neste trabalho apresentar sucintamente dois pontos de vista. O primeiro deles está relacionado a autores brasileiros que trabalham com o conceito, tanto na área clínica quanto na área do trabalho, e às abordagens mente-corpo (Coleman e outros, 1997) que começam a ser difundidas nos meios acadêmicos. Em seguida, apresentaremos algumas críticas quanto à utilização desse termo como um conceito científico, baseando-nos em autores da Escola de Psicossomática de Paris, em Castiel (1994) e em Doublet (1998). Na conclusão faremos alguns comentários sobre-as possibilidades $\mathrm{e}$ as limitações que podem ser depreendidas de nossa breve exposição.

\section{Em Defesa do Conceito de Estresse}

Hans Selye foi o primeiro estudioso que tentou definir estresse, atendo-se à sua dimensão biológica. De acordo com este autor (1959), o estresse é um elemento inerente a toda doença, que produz certas modificaçöes na estrutura e na composiçảo química do corpo, as quais podem ser observadas e mensuradas. O estresse é o estado que se manifesta através da Síndrome Geral de Adaptaçào (SCA). Esta compreende: dilatação do córtex da suprarenal, atrofia dos órgãos linfáticos e úlceras gastro-intestinais, além de perda de peso e outras alteraçóes. A SCA é um conjunto de respostas não específicas a uma lesão e desenvolve-se em três fases: 1) fase de alarme, caracterizada por manifestaçōes agudas; 2) fase de resistência, quando as manifestaçōes agudas desaparecem e; 3) fase de exaustảo, quando há a volta das reações da primeira fase e pode haver o colapso do organismo. Selye afirma que $o$ estresse pode ser encontrado em qualquer das fases, embora suas manifestaçōes sejam diferentes ao longo do tempo. Além disso, não é necessário que as três fases se desenvolvam para haver o registro da síndrome, uma vez que somente o estresse mais grave leva à fase de exaustão e à morte.

Partindo do que o estresse não é, este autor busca definir cientificamente o termo. Entre várias considerações, esclarece que estresse năo é uma tensão nervosa nem o resultado específico da lesão. Além disso, nāo é nada que cause uma reação de alarme (neste caso tratar-se-ia do estressor, ou do agente do estresse), nem é um desequilíbrio da homeostase. Assim, estresse é um estado manifesto por uma síndrome específica, constituída por todas as alteraçōes não específicas produzidas num sistema biológico. Segundo ele, esta é uma definição operacional, que trata do que deve ser feito para se produzir e reconhecer o estresse. Assim, o termo só tem signifiçaçâo quando aplicado a um sistema biológico precisamente definido.

Nesta obra, Selye tenta responder a várias críticas que na época já lhe eram endereçadas. Em vista disso, afirma que a aversão ao termo é parte integrante da história do estresse, pois nesse caso a rejeição do nome é uma das conseqüências principais da incapacidade de abarcar o novo conceito.

Os autores brasileiros Júlio de Mello Filho e Mauro Diniz Moreira (1992) discutem a importância do estado emocional dos pacientes na evoluçăo de doenças infecciosas e neoplásicas. Eles definem estresse (físico, psicológico ou social) como um "termo que compreende um conjunto de reaçöes e estímulos que causam distúrbios no equilíbrio do organismo, freqüentemente com efeitos danosos." (op. cit., p. 121). Acrescentam que, embora Selye em 1936 tenha apresentado o conceito de estresse biológico na Síndrome Geral de Adaptação, posteriormente sua equipe estudou o estresse psicológico e atualmente tem estudado o estresse social. Lazarus (apud Mello Filho e Moreira, op.cit.), por sua vez, conceituou coping como um "conjunto de mecanismos de que o orga-nismo lança mão em reação aos agentes do estresse, representando a forma como cada pessoa avalia e lida com estas agressóes." (p. 121).

Avelino Rodrigues e Ana Cristina Gasparini apresentam num artigo de 1992 uma perspectiva social em psicossomática. Neste trabalho os autores afirmam que às vezes temos a impressão de que o termo estresse tornouse uma panacéia. Percebe-se, assim, uma preocupação com a definição de estresse, para 
não se perder o caráter científico do estudo. Estes autores admitem que existem enormes controvérsias sobre esse assunto. Citam Vingerhoets e Marcelissen, que em 1988 apontaram nove caminhos diferentes na conceituação do estresse. Entretanto não consideram que esta diversidade constitua um problema significativo e afirmam mesmo que

sob uma perspectiva democrática, é algo bastante positivo e até louvável, pois estes vértices não săo excludentes entre si, ao contrário, complementam-se e ajudam a construir um conjunto organizado de conhecimentos, de uma aproximação holistica para a promoção de saúde. $\hat{E}$ aqui, por este vértice da mais recente epistemologia, que se insere o discurso da modernidade em Psicossomática. (op. cit., p.93,94).

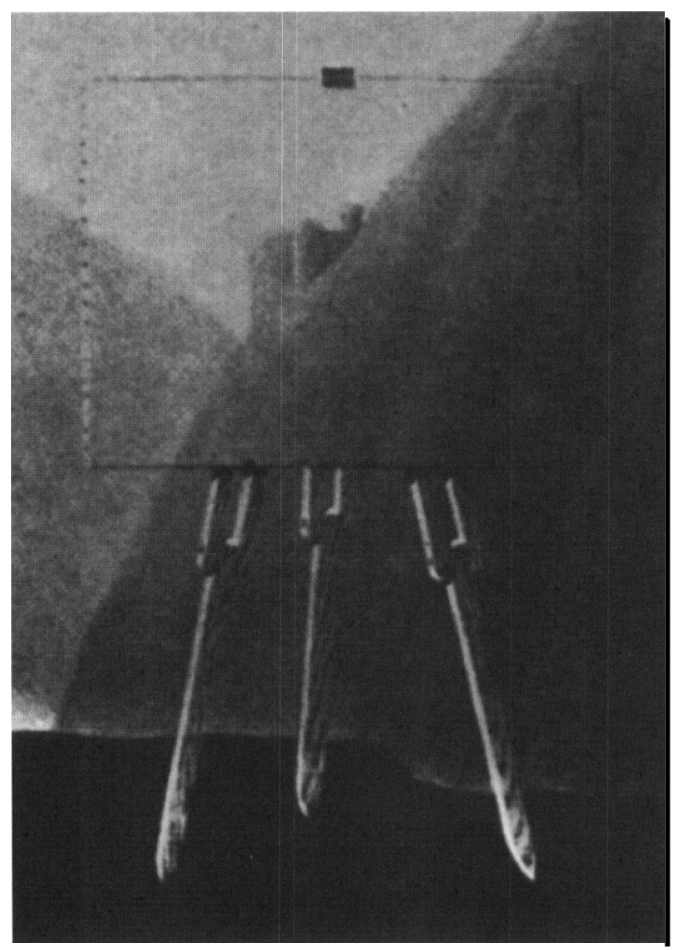

Em outra obra, Rodrigues (1997) traz uma definição de estresse como "uma relação particular entre uma pessoa, seu ambiente e as circunstâncias às quais está submetida, que é avaliada pela pessoa como uma ameaça ou algo que exige dela mais que suas próprias habilidades ou recursos e que pōe em perigo o seu bem-estar" (op. cit., p.24). Esta é uma visão biopsicossocial do estresse, que considera os estímulos estressores provenientes tanto do meio externo (estímulos de ordem física ou social, como o trabalho), quanto do interno (pensamentos, emoções, fantasias e sentimentos, como angústia, medo, alegria e tristeza).

O autor cita as três fases do estresse biológico especificadas por Selye na Síndrome Geral de Adaptaçāo e admite a participação do indivíduo no aumento do estímulo estressor. Segundo ele, a probabilidade de adoecimento vai depender do como este indivíduo avalia e enfrenta esse estímulo, bem como de sua vulnerabilidade orgânica.

Rodrigues afirma ainda que, no processo de avaliação dos estímulos estressores, há uma atividade mental que em parte é racional e em parte emocional, năo necessariamente consciente. Isso vai determinar o tipo de enfrentamento, ou como o indivíduo responderá a esses estímulos, considerando seu repertório de experiências passadas. Segundo o autor, os compromissose as crenças são fatores pessoais que influenciam nesse processo de avaliação. Além desses, são também importantes os componentes situacionais dos estímulos, como o caráter de novidade da situação, a previsibilidade do acontecimento, sua intensidade, etc. $O$ enfrentamento é definido como a estratégia ou conjunto de esforços de que o indivíduo lança măo para dominar a situação estressante.

O autor faz a distinçāo do que seria uma boa quantidade de estresse, o eustresse, que levaria o indivíduo a ser mais produtivo e criativo nas suas respostas adaptativas, e o que implicaria numa quantidade inadequada de estresse, 0 distresse, correspondendo a um excesso ou a uma insuficiência deste estado, levando o indivíduo a apresentar respostas inadequadas, ou paralisando-o.

Marilda Lipp (1984), dentro de uma abordagem cognitivo-comportamental, define o estresse como "uma reação psicológica, com componentes emocionais físicos, mentais e químicos, a determinados estímulos que irritam, amedrontam, excitam e/ou confundem a pessoa" (op. cit., p. 6). A autora distingue o nível de estresse excessivo ou insuficiente (distresse), daquele que é necessário para o bom desempenho da pessoa (eustresse). Ela 
considera as características reais dos estímulos e/ou a ação interpretativa que o sujeito dá aos mesmos na determinação do distresse ou do eustresse. As primeiras características envolveriam um processo metabólico ou sensorial sem a participação de mecanismos cerebrais interpretativos; a segunda seria proveniente do componente aprendizagem, do repertório de condicionamento de respostas que a pessoa acumulou durante a vida.

Dentro desta perspectiva de aprendizagem de reaçôes diante dos estressores, Lipp recomenda o tratamento comportamental do estresse excessivo, que se dá em três frentes: 1) ajudando o cliente a desenvolver e implementar estratégias para modificar sua interpretação dos estressores; 2 ) ajudando o cliente no desenvolvimento e implementação de táticas para a reduçâo da reação psicofisiológica excessiva; e 3) ajudando o cliente na implementaçāo de técnicas apropriadas de expressão e utilização de respostas de estresse. Na primeira etapa do tratamento, faz-se o levantamento dos sintomas presentes (tipo, intensidade e freqüência\}, incluindo neste inventário sete sintomas físicos e sete mentais. $\mathrm{Na}$ segunda, tem-se a discussão com o cliente sobre o conceito de estresse, $o$ da resposta de estresse, e o da importância das idéias irracionais. $\mathrm{Na}$ terceira e última etapa, o tratamento propriamente dito consta do treino de relaxamento, da modificação de verbalizaçōes inadequadas, da reestruturação de crenças irracionais, do desenvolvimento de métodos de resolução de problemas, da programação de atividades físicas adequadas ao tipo de sintoma encontrado e da recomendação de uma dieta especial.

Carl Simonton e colaboradores (1987), abordam o conceito de estresse relacionando-o a estados emocionais provenientes da reaçăo pessoal dos indivíduos frente a mudanças significativas em suas vidas. Citam pesquisas sobre o câncer, nas quais indicam uma possivel ligação entre a quantidade de estresse e a predisposição às neoplasias. Lembram que, para o paciente canceroso, estas descobertas são muito importantes, pois o sistema imunológico é sensível ao estado emocional, e este pode fortalecer ou suprimir aquele. Mas o que realmente parece ser significativo, concluem, é a maneira como cada pessoa reage aos agentes estressores, sendo este um fator decisivo para o aparecimento ou a evolução de doenças.

Os autores citam a "Escala de Agentes Estressores" estabelecida por Holmes e Rahe, incluindo tanto acontecimentos considerados negativos, como morte do cônjuge e prisão, quanto positivos, como nascimentos e casamentos. Ressaltam a qualidade comum

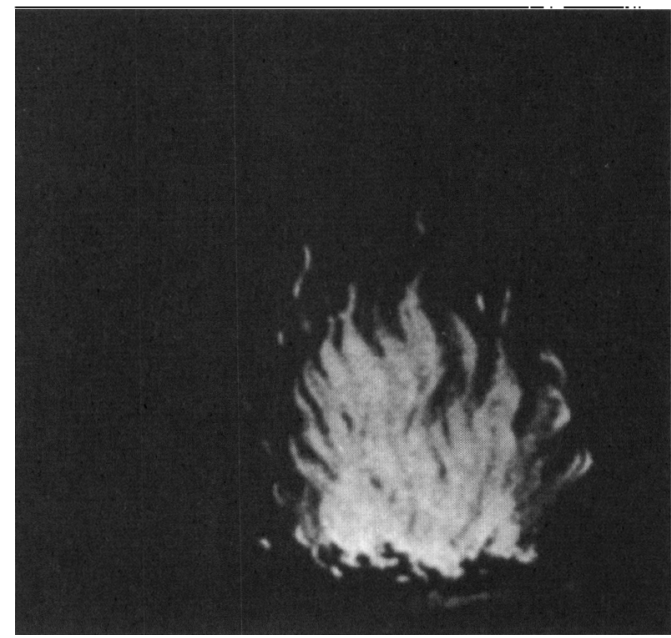

destes agentes de implicarem sempre numa mudança de hábitos, de relação com as pessoas e com a auto-imagem, e na conseqüente adaptaçāo do indivíduo a estas mudanças. Inferem, daí, um possível movimento introspectivo do indivíduo a algum conflito emocional não solucionado. Vê-se aqui claramente uma certa "interiorização" do esquema simplista estímulo-resposta, ao considerar a maneira subjetiva do indivíduo a "modular" a intensidade dos agentes estressores.

Ainda que o plano de análise dessas pesquisas firme-se nos processos físico-químicos decorrentes da reação ao estresse, alterando a homeostase orgânica e predispondo às doenças, inclusive às infecto-contagiosas, os autores dāo uma grande importância ao acúmulo dos produtos da reação ao estresse (estresse crônico), sendo estes subjacentes às características pessoais e à história de vida dos indivíduos. A maneira como estes indivíduos enfrentaram as situações estressantes, "traumáticas" na infância, in-fluenciaria um tipo de resposta, nem sempre satisfatória, de lidar 
com estas emoçôes na vida adulta, que estaria estreitamente vinculada às crenças formadas.

Dando continuidade a este enfoque, tem-se o que hoje está sendo denominado de psiconeuroimunologia, como nos apresentam Goleman e outros (1997). Os autores desta linha investigativa consideram importante tanto as reaçōes endócrino-químicas a que o corpo está sujeito por conta das diversas emoções que o indivíduo experimenta (secreção de catecolaminas, numa resposta simpática do sistema nervoso autônomo, ou mesmo, um aumento do funcionamento parassimpático, devido a uma perda na vida do indivíduo, levando a uma depressão), quanto o papel que a mente desempenha no surgimento e administração destas emoçōes. Os autores reconhecem a dificuldade de uma definição unânime do conceito de estresse, porém aqui ele é acordado como sendo a reação que uma pessoa apresenta ao que lhe acontece, existindo, contudo, uma relação indireta entre estresse e doença, visto que cada indivíduo reage de modo diferente aos fatores estressores.

Pelletier (1997) afirma que fatores como sexo, raça, personalidade, formação genética, além de fatores sociais e psicológicos, podem estar envolvidos no processo de morbidez frente a estímulos estressores. Acrescenta que o controle sobre os agentes estressores possui um importante efeito sobre a saúde.

Como se vê, esta abordagem se insere no rol das que procuram integrar mente-corpo, levando em conta os processos internos subjetivos, onde as linhas de tratamento vão da meditação, passando por diversas técnicas de relaxamento, de visualização e chegando ao biofeedback, promovendo o "estado reparador" do organismo, resultante da atuaçăo do sistema nervoso parassimpático. Pelletier enfatiza a importância das pesquisas nesse campo para que se possa esclarecer qual é o papel de certos fatores difíceis de medir, como as crenças e os valores, na saúde do sujeito. Afirma ainda que

Embora esses assuntos possam parecer uma fútil especulação filosófica, são cruciais para o bemestar psicológico, para a saúde física e para o futuro desenvolvimento de um sistema de saúde verdadeiramente eficaz (op.cit., p. 29).

Nesta perspectiva podemos incluir ainda o trabalho de Rossi (1994). Este autor faz uma revisāo do estresse e da SGA apresentados por Selye e, desta forma, defende a utilizaçāo do conceito. Segundo Rossi, a primeira contribuição original de Selye foi mostrar que, qualquer que seja a fonte do estresse biológico intrometendo-se no organismo, ele reage com o mesmo padrăo de resposta para restaurar a homeostase interna. Este autor propōe um entendimento mais amplo da teoria do estresse, que se distancie do ideal de prediçāo e controle característico das abordagens behavioristas supersimplificadas de estímuloresposta.

Rossi refere-se a Sapolsky, segundo o qual o terceiro estágio de Selye (exaustão) não está correto, porque o estresse crônico não leva o organismo a uma exaustão das moléculas mensageiras de ativação do estresse, tais como epinefrina e cortisol. O que acontece de fato é o contrário: é o excesso crônico dessas substâncias ao longo do tempo que leva a uma eventual ruptura coletiva das partes do binômic mente-corpo, chamada de resposta de estresse ou psicossomática.

Ele propōe uma Síndrome Geral de Adaptação em dois estágios em vez de três. $O$ primeiro estágio seria caracterizado por uma resposta adaptativa complexa de alarme e ativação, enquanto a segunda fase seria constituída a partir das eventuais conseqüências desajustadas da resposta de estresse prolongado, quando a ativação se tornasse crônica.

De acordo com Rossi, a síndrome de Selye não teria um caráter tão inespecífico, porque hoje acredita-se que diferentes estressores, vivenciados pela mente-corpo, podem liberar diferentes combinaçōes dos mensageiros ativadores do estresse para serem enviados ao hipotálamo.

\section{Críticas ao Conceito de Estresse}

A Escola de Psicossomática de Paris (EPP) vai dar ênfase ao aspecto subjetivo do adoecer, divergindo do enfoque das teses agressológicas. 
Estas, como se baseiam no esquema estímuloresposta, não consideram outras facetas do adoecer fora das reações fisiológicas. Déjours e colaboradores (1980), integrantes da EPP, argumentam que, nessas teses, nảo existem diferenças sutis entre as formas de adoecer. deixando à diferença qualitativa dos estímulos uma parcela desprezível neste processo - o nascimento de uma criança ou o luto pela perda de um ente querido seriam encaradas nos termos das reações endocrinológicas, que poderiam ser semelhantes deste ponto de vista, mas não do sujeito que vivência estes acontecimentos.

Com base na Psicanálise, esta escola vai procurar nos sujeitos a diferença fundamental que faz com que certos indivíduos sejam mais propensos ao adoecer do que outros, embora sujeitos às mesmas condiçōes de vida ou história familiar. Assim, determinados sujeitos apresentariam uma maior resistência (nâo no sentido psicanalítico do termo) quanto às somatizaçōes, no sentido do adoecimento, por possuírem uma estrutura mental melhor aparelhada para enfrentar os traumas - e não o estresse - ainda que não estejam totalmente imunes às doenças.

Talvez uma das diferenças fundamentais da Escola de Paris em relação às teses agressológicas, além de seu embasamento teórico mais compreensivista e hermenêutico, seja a procura da não dicotomia do humano em ser psicológico e ser biológico. Ela faz uma análise da dinâmica do sujeito, considerando-o como uma "unidade dúplice", como o é a luz, que tem duas naturezas, sendo constituída por ondas eletromagnéticas e ao mesmo tempo por partículas, os fótons.

A origem destes estudos remonta a Freud, com a noção de neurose atual, em que certos sintomas físicos não têm uma correspondência simbólica com conflitos sexuais infantis do sujeito (como ocorre na histeria), constituindose por uma manifestação de uma angústia difusa, com fenômenos funcionais dispersos (cefaléias, vertigens, excitaçòes cardiorespiratórias,...) provenientes de uma estase libidinal, de uma nảo resoluçāo, ou de uma resoluçăo insatisfatória de excitações sexuais no presente (Volich, 1998). A partir disso, Pierre Marty vai inaugurar uma nova teoria e prática clínica, procurando compreender este modelo de patologia somática não correspondente à histeria. Tem-se, então, o desenvolvimento de conceitos fundamentais a esta escola, como a função de regulação psicossomática que o aparelho psíquico e suas funçōes possuem. $O$ pensamento operatório e a depressão essencial sâo outros dois conceitos centrais nesta linha de trabalho, correspondendo respectivamente a um pensamento "desafetado", com uma pregnância do real em detrimento do fantasístico, do subjetivo, e uma depressão sem luto, sem objeto, correspondendo a uma sensação de vazio representacional.

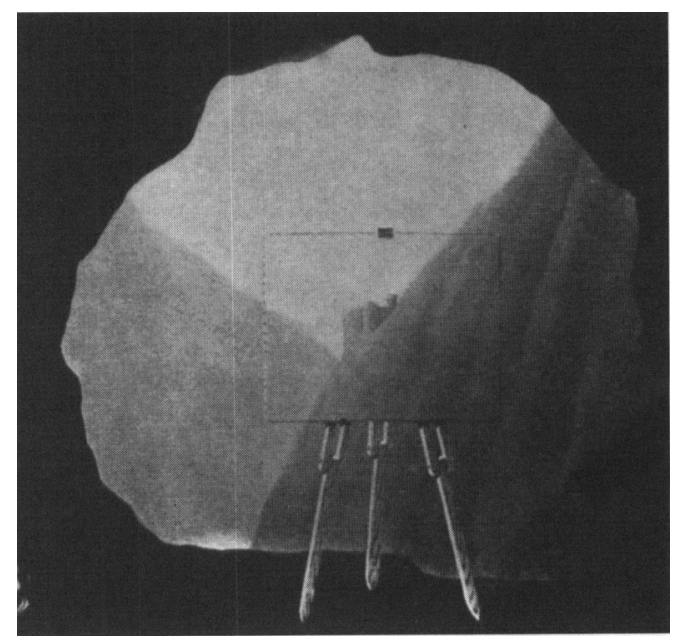

É dentro de uma perspectiva ontogenética evolutiva que Marty vai conceber o desenvolvimento do ser humano, num contínuo especializar-se e diferenciar-se de órgãos e funçōes, rumo a uma complexidade crescente. A gênese do psiquismo se coloca dentro desta evolução, com o seu desenvolvimento progressivo a partir do nascimento do bebê, com a mãe fazendo-se de anteparo protetor para os estímulos intrusos que chegam até ele, externos ou internos, e ajudando-o a representá-lose nomeá-los adequadamente. É, pois, da sintonia entre a acolhida pela mãe das necessidades da criança e sua adequada resposta (elaborados pela função alfa da mãe, se quisermos colocar em termos bionianos) que pode depender a integridade da função mental (Kreisler, 1978).

Desta forma, estes autores vão tirar a ênfase do fator externo, colocando o peso do 
fenômeno na capacidade ou não de mentalização do sujeito (defesas mais sofisticadas). Caso essas mentalizaçôes não sejam suficientes, dejxariam às pulsões uma única via de resoluçào, arcaica quanto ao funcionamento: o corpo. Neste caso, o conflito psíquico neurótico năo chega realmente a ter palco, uma vez que não há uma interiorização do que pode estar ocorrendo com o indivíduo.

Assim, o eixo central desta abordagem é o ponto de vista econômico, uma vez que a quantidade de excitações endógenas (pulsão) que năo chegam a ser representadas, deixaria o sujeito num estado de aflição somática (nảo ansiosa, por não ter material mentalizado a ser conflituado), o que também pode ser causado por uma situação concreta à qual o sujeito não pode responder adequadamente. Os autores pontuam que em vista desta falha do indivíduo em dar uma representação mental ao que the está acometendo, pôe-se em curso um processo de desorganização mais amplo, proveniente da pulsão de morte.

Nesta abordagem, verificamos que o conceito de estresse não é adotado. De certa forma, encontramos em seu lugar o conceito de trauma psíquico, característico da dinâmica do sujeito frente à simbolização do real.

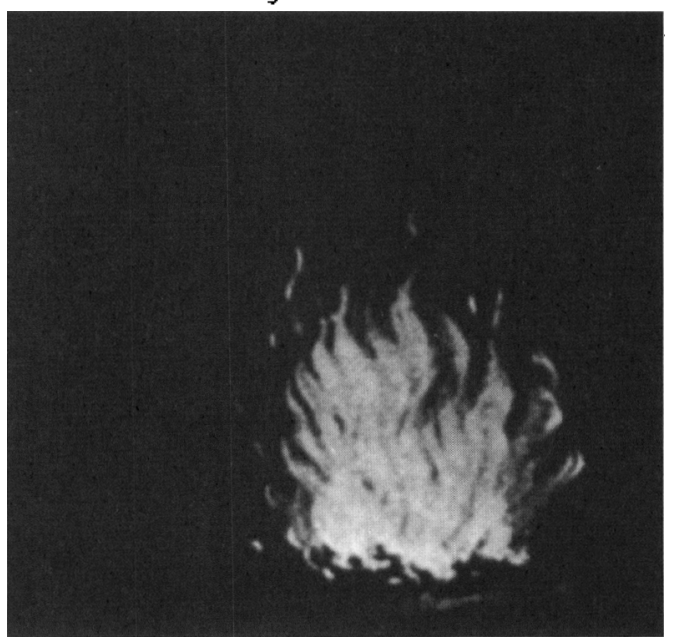

Cunha e Almeida (1992), numa crítica ao conceito de estresse apresentada no VIII Congresso Brasileiro de Medicina Psicossomática, colocam-se sob esta mesma perspectiva psicanalítica, que considera o sujeito como o eixo central de sua problemática, e não como uma máquina que responderia indistintamente a estímulos. As autoras lembram que desde que o conceito de estresse foi definido por Selye em 1936, o seu significado original tem sido tomado de maneiras diversas. Originalmente corres-ponderia a uma reação do organismo frente a agentes estressores externos que provocaria um aumento do nivel de exigência aos seus "recursos", afetando a sua capacidade de equilibração interna. Com o continuar deste estado, o organismo entraria em fatência adaptativa e adoeceria. Hoje não se tem uma clareza sobre o que realmente significa estresse, sendo este referido muitas vezes a um estado passageiro de cansaço ou tensão, ou ainda, a um distúrbio obscuro e duradouro. Outras vezes tomam-se os agentes estressores no lugar do estado produzido por estes. Citam ainda Debray (1984) que alerta para a possibilidade do conceito ser tomado tanto no sentido do modelo agressológico (modelo médico), como no sentido da perda ou luto (modelo psicanalítico).

As autoras acreditam que por trás desta verdadeira profusão de significados pode estar uma tentativa de enquadramento e o conseqüente afastamento da história singular destes sujeitos ou, ainda, uma forma de evitar os conf́itos presentes no campo da psicossomática que se constituem entre a formação médica e a formação psicanalítica.

De acordo com Castiel (1994), no campo das pesquisas biomédicas e epidemiológicas, a teoria do estresse se constitui num dos referenciais explicativos para abordar o processo saúde-doença. Segundo ele, o termo em inglês stress, que vem da mecânica, já encerra ambigüidades que não toram contornadas na conceituação biológica. Em primeiro lugar, o termo pode ser entendido como uma força exercida sobre um corpo que tende a deformarse, ou como a intensidade dessa força. Pode também ser entendido como uma tensāo mental ou físiça, a urgência ou a pressão que a causa. Assim, observa-se que o mesmo termo refere-se tanto à causa quanto ao efeito. $\mathrm{O}$ estresse pode também ser indicativo da resposta biológica a estímulos perturbadores de uma situação estável (situação de homeostase). Neste trabalho, o autor procura mostrar a amplitude de uso do conceito de estresse, independente das orientaçōes teóricas de seus autores, e questiona se estes autores estariam se referindo à mesma coisa. 
No plano metodológico, Castiel desenvolve uma argumentação segundo a qual não há como discutir a relação entre o estresse e a doença em termos genéricos, de forma que o máximo que podemos fazer é falar da relação entre formas específicas de estresse e doenças específicas. Além disso, afirma que há problemas no que se refere à validade dos métodos de mensuração dos fatores de interesse, e que os mecanismos etiopatogênicos ainda não estão bem entendidos. Questiona ainda se diferentes fatores psicossociais considerados estressores provocariam patologias específicas distintas.

Segundo este autor, a teoria do estresse propóe explicações com suporte neuro-humoral que confundem o como de uma patogenia com o porquê tal evento ocorreu com determinada pessoa. Assim, para a teoria do estresse não interessa a subjetividade do estressado; a ênfase é no mensurável, tornando a experiência subjetiva muitas vezes acessória.

Por outro lado, Castiel afirma que a noçăo de estresse é pertinente em situaçōes extremas, como guerras e catástrofes. Fora delas, 0 conceito se tornaria controverso, e traria dificuldades para as pesquisas biomédicas. Afirma ainda que o conceito se ampliou de tal forma que praticamente perdeu seu sentido, tornando-se na verdade uma entidade polissêmica.

Abordando também o aspecto desta multiplicidade de sentidos e suas implicaçōes, o psicólogo Serge Doublet (1998) vem tratando dos problemas relativos ao uso científico do conceito de estresse em sua tese de doutorado. Segundo este autor, são oferecidos muitos pontos de vista sobre o que é estresse, muitas vezes contraditórios, resultando numa grande confusão. Neste trabalho, Doublet parte do princípio de que o estresse não é um conceito legitimado. Segundo ele, conceitos como ansiedade, conflito, frustração, distúrbio emocional, alienação traumática e anomia, têm sido descritos como estresse e grande parte da confusáo é devida à tentativa de se agrupar sob um só conceito ocorrências diversas $\mathrm{e}$ complexas. Não havendo um acordo em torno do que seja estresse, sua utilidade é discutida enquanto conceito.

Para este autor, as próprias definiçōes de estresse são uma fonte de discordância e de confusáo. O problema que parece ser central, de acordo com Cox (apud Doublet, op. cit.) é o fato deste conceito ser familiar tanto para o leigo quanto para o profissional. Dessa forma, quando usado num sentido mais amplo, é entendido por todos, o que não ocorre quando é usado num sentido mais preciso. Doublet afirma que encontram-se vinte e oito significados para o termo stress no dicionário Oxford Long English Dictionary. Entre eles, há uma definição psicológica e biológica, que descreve estresse como uma circunstância

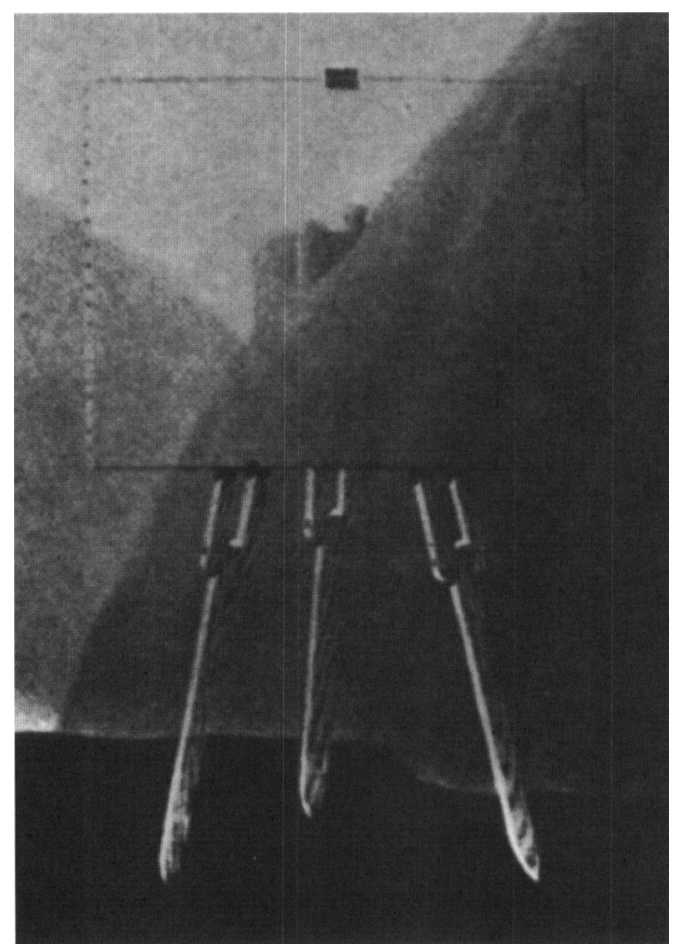

adversa que perturba o funcionamento fisiológico de um indivíduo, mas também como o estado perturbado que daí resulta. O termo estressor, por outro lado, parece não sofrer a mesma indefinição e é creditado a Hans Selye em 1950.

De acordo com Doublet, Selye foi o primeiro a conceituar estresse da forma que o entendemos atualmente. Admitindo seu conhecimento insuficiente da língua inglesa, Selye afirmou que talvez strain pudesse ser um termo mais apropriado que stress. Doublet afirma que esta troca poderia ter nos poupado de grande parte da confusão atual em torno do conceito. 
Duas das principais teorias são as de Holmes e Rahe (1967), que enfatizam a importância dos estímulos externos - estressores - e Lazarus (1976), que enfatiza a importância da capacidade do indivíduo para lidar (cope) com o estresse. Essas teorias são representativas das controvérsias existentes. $\mathrm{O}$ mais perturbador disso tudo, segundo Doublet, é a utilização indiscriminada de certos aspectos das teorias que experts têm lançado mão em seus programas para o controle do estresse. Esses programas introduzem também o aspecto motivador segundo o qual uma certa quantidade de estresse é desejável. A pergunta que ainda não foi respondida é: qual é a quantidade de estresse desejável? Este problemas quanto ao propósito do corpo em manter um equilíbrio. Dessa forma, provar a causalidade de propósito, próprio das teorias teleológicas, está fora do escopo da ciência que está assentada sobre a construção de hipóteses testáveis, portanto passíveis de refutação. Se o propósito do equilíbrio de um organismo (homeostase) não pode ser testado, provado ou refutado, porque é um propósito filosófico, então qualquer teoria científica que se baseie em compensações e ajustes fisiológicos decorrentes deste argumento sāo especulativas, inviabilizando as explicaçôes daí decorrentes.

O autor critica também alguns aspectos

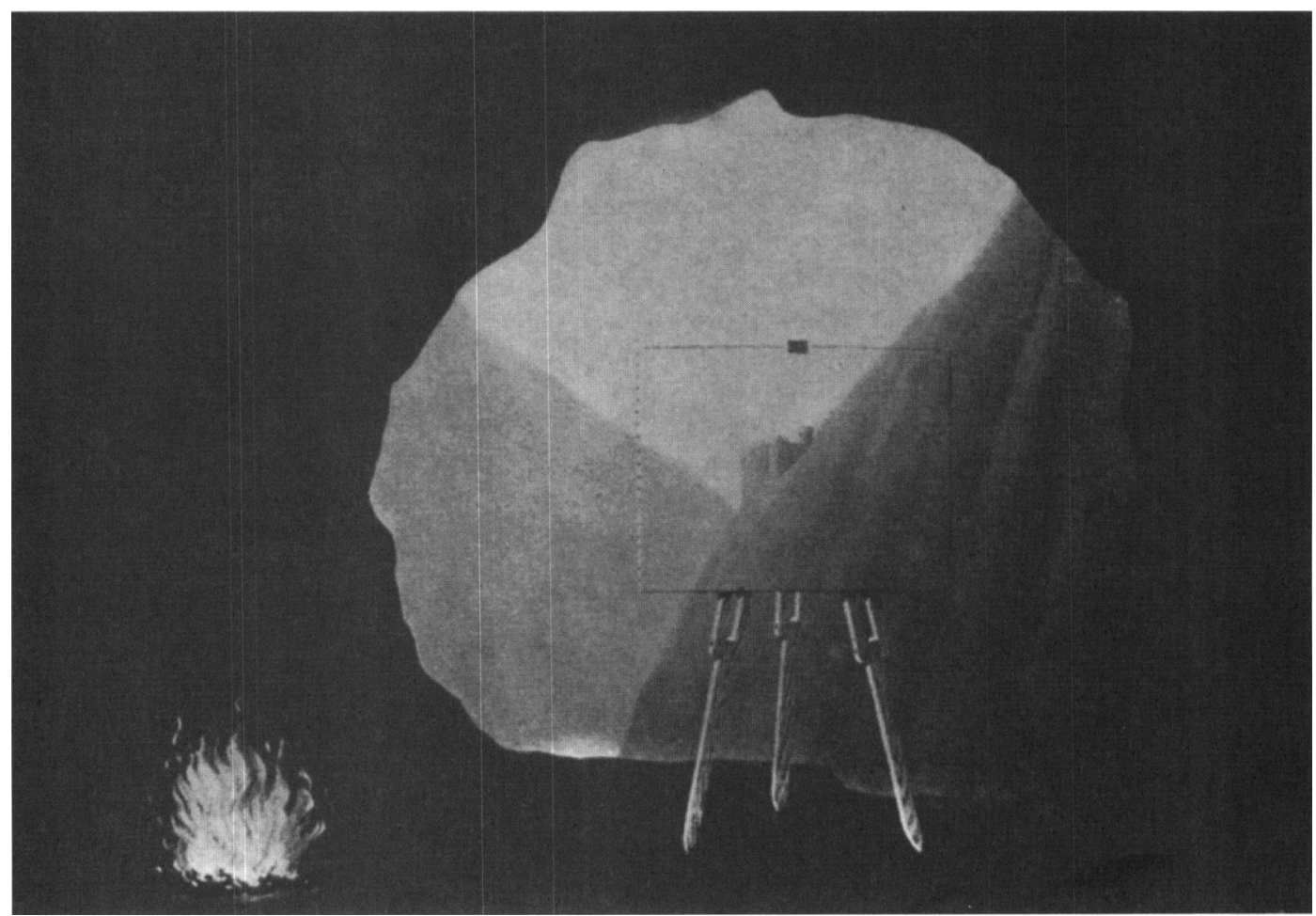

questionamento pode ser estendido às abordagens de Rodrigues e de Marilda Lipp, que aposta nesta quantidade nâo especificada de estresse saudável.

O autor afirma ainda que, sendo o conceito de estresse proposto por Selye intrinsecamente ligado à existência de uma homeostase interna (termo cunhado por Cannon referindo-se ao caráter compensatório metodológicos dos estudos sobre estresse, como a confiabilidade dos relatos retrospectivos dos pacientes sobre o início de suas doenças, além do fato de ambos, pacientes $\mathrm{e}$ pesquisador poderem estar se referindo a coisas diferentes, dada a falta de definição do conceito. Alguns dos pressupostos em que se baseiam os estudos sobre o estresse também são discutidos, como a distinção entre estresse físico e estresse psicológico, e o pressuposto relacionado à validade dos estímulos considerados estressores. 


\section{Conclusão}

Podemos perceber que muitas das críticas apresentadas pelos autores na terceira parte deste trabalho não têm uma resposta exata dos defensores da teoria do estresse. Estes, por sua vez, parecem adotar uma definição que pode ser considerada precisa dentro do contexto considerado. Entretanto, em se tratando da saúde e do adoecimento do ser humano, nāo podemos deixar de levar em consideração a complexidade desses processos, que envolvem não só as dimensóes observáveis, como também as dimensões subjetivas dos indivíduos. Sendo o estresse um processo com características gerais, como o definiu Selye na Síndrome Geral de Adaptaçāo, entendemos que ele não deve ser restrito às suas características observáveis e mensuráveis. Entretanto, isso realmente traz implicaçōes científico-metodológicas.

Certamente não é à toa que o conceito ainda persiste após todos esse anos, como bem lembrou Doublet. Se isso acontece, deve haver algum mérito em sua utilização. Selye justifica sua teoria afirmando que, em termos científicos, uma teoria que não se ajuste perfeitamente aos fatos observados é falha, mas mesmo assim pode ser útil enquanto outra nāo for desenvolvida, de forma que uma teoria na verdade só é substituída por uma methor. Esse é o argumento da posição coerentista de justificação das crenças. Talvez esta seja a melhor forma de olharmos para a teoria do estresse.

De acordo com Selye, o valor principal da SGA é justamente o de proporcionar uma base comum que unifica todas as observações feitas sobre o fenômeno, até então aparentemente não relacionadas. A crítica que pode ser feita refere-se justamente à tentativa de abarcar vários fenômenos diferentes sob um único conceito, relacionando coisas que não deveriam ser relacionadas. Isso seria uma forma de simplificação que obliteraria o verdadeiro entendimento desses fenômenos.

Selye afirma que seus argumentos iniciais em defesa de sua teoria, e portanto em defesa do conceito de estresse, não convenciam muita gente. Segundo ele, foi apenas gradualmente, mais por meio da força do hábito que da lógica, que o termo estresse caiu em uso corrente, enquanto o próprio conceito se converteu num popular assunto de pesquisa. Verificamos assim que ele mesmo reconhecia a relativa fragilidade de seus argumentos.

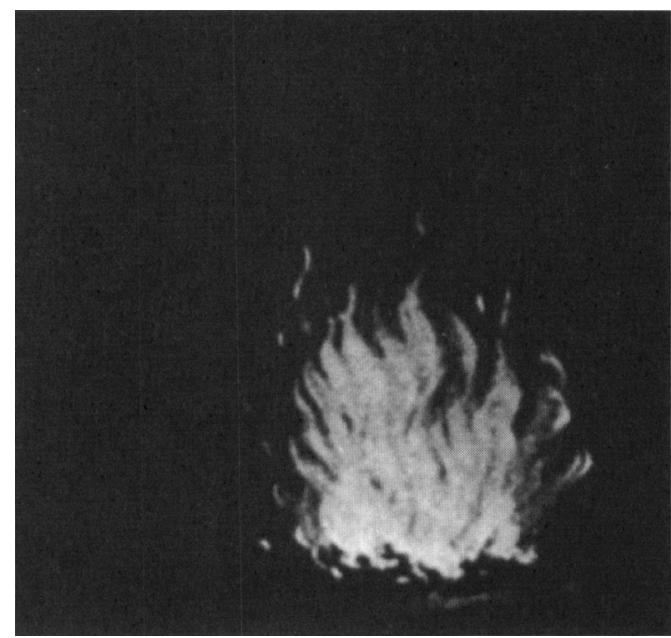

Podemos depreender de tudo isso que, de acordo com o enfoque adotado, teremos formas diferenciadas de entender e abordar o fenômeno. Assim, de uma base eminentemente cognitivo-comportamental, teremos um reducionismo que poderá deixar de lado questōes mais amplas da dinâmica simbólica do sujeito frente a si e ao mundo, ao contrário do que nos propóe a Escola de Psicossomática de Paris. Entretanto, essas abordagens não deixam de ter um efeito terapêutico, digamos, mais dinamizado, importante sobretudo nos casos emergenciais e/ou situacionais em que o fenômeno estresse se apresente. Entendemos que o trabalho de Marilda Lipp pode ser enquadrado nessa linha. Esse efeito terapêutico é, no entanto, questionado pelos profissionais que trabalham sob o vértice psicanalítico que vêem no sintoma o elo por onde o sujeito se encontra enganchado, por onde ele se estrutura de alguma forma e, também, por onde este sujeito pode trabalhar psiquicamente a fim de tomar contato e ampliar o seu conhecimento em relação a si próprio, abrindo novas possibilidades relacionais intra $\mathrm{e}$ intersubjetivas. Os autores desta linha ainda advertem sobre a possibilidade da volta do sintoma, por não ter sido tocada a sua causa, argumento que também não apresenta suficientes estudos e pesquisas comprobatórias de sua validade. 
Por outro lado, dentro da própria Escola Francesa de Psicossomática há produçõoes que vão se diferenciando umas das outras, mostrando que este campo de investigação, embora dê muitos sinais de êxito, está somente no início dos trabalhos. O próprio Déjours (1993) nos diz em que sua posição se difere da dos psicanalistas do Instituto de Psicossomática de Paris: é no que tange à atribuição de sentido ou não sentido do sintoma somático. ísso nos leva a pensar que o conceito de estresse não é usado, ou melhor, criticado da mesma forma pelos diversos autores desta escola.

Assim, qual seria o valor das pesquisas que utilizam o conceito de estresse? Se este conceito é um equívoco, qual é o uso que podemos fazer dos resultados que os pesquisadores nos oferecem? Por outro lado, será que nada se salva, ou seja, será que o trabalho de tantos profissionais dedicados, que têm conseguido fazer alguma coisa para melhorar a vida de algumas pessoas, não tem valor algum?

Este tipo de discussāo nos leva à complexidade do ser humano e à necessidade de uma reflexão ético-filosófica que procure situar o pesquisador-cientista-profissional diante desta multiplicidade de sentidos e posições, numa visão sempre multidisciplinar dos fenômenos relacionados aos processos da doença e da saúde.
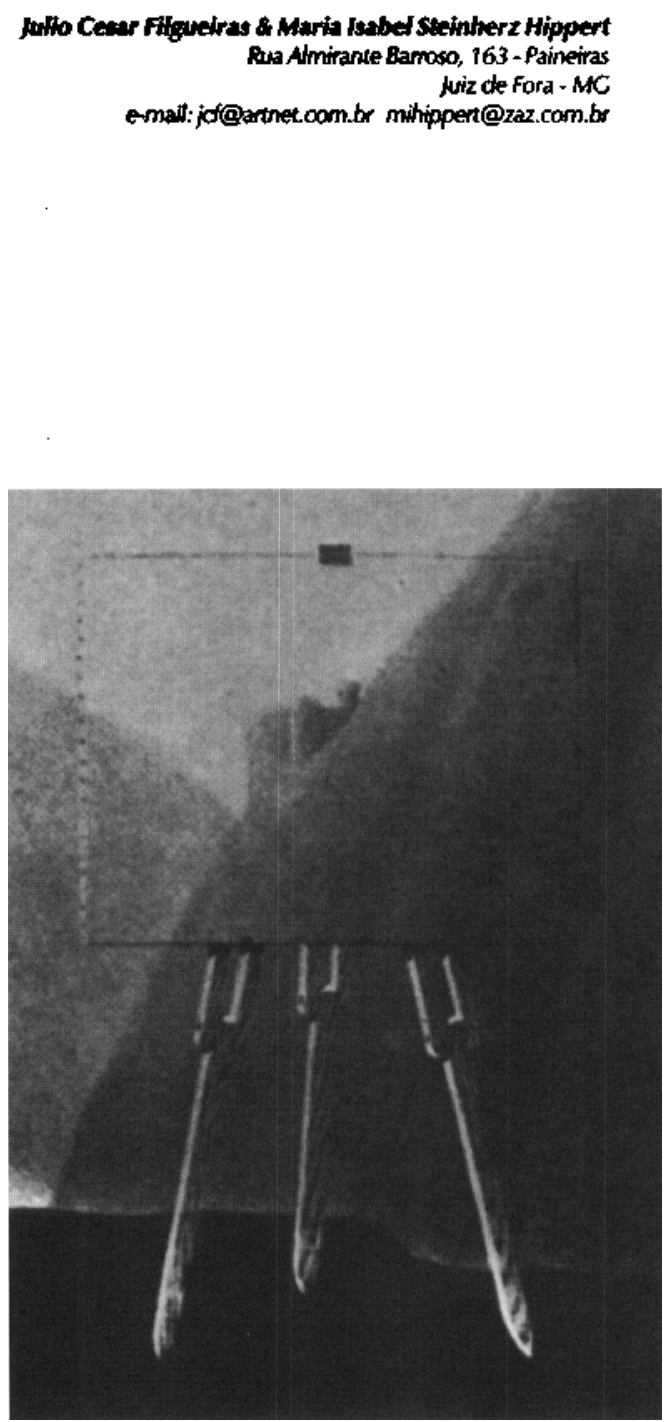
Recebido em 18/11/98 Aprovado em 2/10/99

Castiel, L. D. (1994). O stress na pesquisa biomédica eepideniológica: as limitaçóes do nrodelo de risco no estudo do processo saúde-doença. in: _. O buracoe o avestruz; a singularidade do adoecer humano. campinas: papirus, p. 127-69.

Cunha, M. S. R. da.; Almeida, C. \{1992\}. Oconceito de "stress"; uma reflexằ crítica, trabalho apresentado no VIII congresso brasileiro de medicina psicossomática, Sào Paulo.

Déjours, C.; Marty, p.; Hercherg-Poloniedka (1980) Questzes teónicas em psicossomática. encycl méd. chir, paris. psychiatrie. $37400 \mathrm{c10.7-}$ trad. pedro henrigue bernardes rondon (mimeo, s/d).

Déjourș, c. (1993). As doenças sornáticas: sentido ou não-sentido? Cliniques Mediterranéemes. Toulouse, $37 / 38$.

Doublet, s. (1998). The problems with stress. Artigo publicado na WEB no enderego hitp://www, freeyellow.com/members $5 /$ sdoublet/ problem.hum, texto disponivel em setembro de 1998.

Goleman, D. \&; Gurin, j. (orgs.) (1997). Equilfrio mente-corpo; como usar sua mente para uma saúde melhor. 2a, ed. rio de janeiro: campus.

Krejsler, L (1978). Acriança psicossomática. Lisboa: editorial Estampa Ltda.

Lipp, M. e. N. (1984). Stress e suas implicagōes. Estudos de Psicalogia, Campinas, v. 1, n.3 e 4, p. 5-19, agofdez.

Moreira, M. D. \& Mello Filho, f. de (1992). Psicoimunolagia hoje. in: Mello Filho, j. de. (org.) . Psicossomática hoje. Porto Alegre: Artes Médicas, p.119-51.
Pelletier, K. Entre a mente eo corpo: estresse, emogôes e saúde. in: Goleman, D; Gurin, J. (orgs.) (1997). Equilhbriomente-corpo; como usar sua mente para uma sacide methor. $2 \mathrm{a}$ ed. Riode laneiro: Campus, p. $15-31$.

Rodrigues, A. Stress, trabalho e doenças de adaptaçóo. in: Franco, a.c.l. \& Rodrigues, a.l. (1997). Stress e trabalho: guia prático com abordagem psicossomatica. Såo Paulo: Adtas, cap. 2.

Rodrigues, A. L. \& Gasparini, A. C. L. F. (1992). Uma perspectiva psicossocial em psicossomatica: via stress e trabalho. in: Mello Filho, 1. de (org.) Psicossomatica hoje. Porto Alegre: Artes Médicas, p. 93107.

Rossi, E. L. (1994). A Psicobiologia de cura mente-corpo. campinas: Editorial Psy II.

Selye, H. (1959). Stress, a tensâo da vida. São Paulo: Iterasa - Instituiçăo Brasileirà de Difúsäo Cultural.

Simonton, $C_{. ;}$Matthews-Simonton, S.; Creighton, J.L. (1987). Coma vida de novo; uma abordagem de auto-ajuda para pacientes com câncer. 6a. ed. Sầo Paulo: Summus.

Volich, R. M. Fundamentos Psicanalî̉oos da Clínica Psicossomática. in: Volich, R. M.; Ferraz, F. C.; Arantes, M. A. de A. C. (orgs) (1998) Psicossoma II - Psícossomática Psicanalítica. São Paulo: Casa do Psicólogo.
Referências bibliográficas 